\title{
Utility of Drug Discovery in Medicinal and Organic Chemistry
}

Prakash Prajapat ${ }^{*}$

Department of Chemistry, Mehsana Urban Institute of Sciences, Ganpat University, Mehsana-384012, Gujarat, India

*Corresponding author: Prakash Prajapat, Department of Chemistry, Mehsana Urban Institute of Sciences, Ganpat University, Mehsana-384012, Gujarat, India, Tel: 07891554090; E-mail: psp04@ganpatuniversity.ac.in

Received date: November 06, 2017; Accepted date: November 06, 2017; Published date: November 13, 2007

Copyright: (C) 2017 Prajapat P. This is an open-access article distributed under the terms of the Creative Commons Attribution License, which permits unrestricted use, distribution, and reproduction in any medium, provided the original author and source are credited.

\section{Editorial}

Drug design is a creative science, a special technology, and an art all in one. Design of highly proficient chemical reaction sequences that give functionalized bioactive heterocyclic motifs with interesting pharmacophoric properties is a major challenge of recent drug discovery. Organic synthetic and medicinal chemists are screening a large number of newer molecules in the lab but very few can pass through the vigorous journey of drug discovery pipeline from lab to market. The pipeline of drug discovery from idea to market consists of seven basic pathways: disease selection, target selection, lead molecule identification, lead optimization, preclinical trial testing, clinical trial testing and pharmacogenomic optimization. In present academia, biochemical, and pharmaceutical industry all contribute to drug discovery. The important for the pharmaceutical and biochemical industry to discover breakthrough drugs is matched by the increasing number of first-in-class drugs approved in recent years and reflects the impact of modern drug discovery, methods, technologies, and genomics [1-4] (Figure 1).

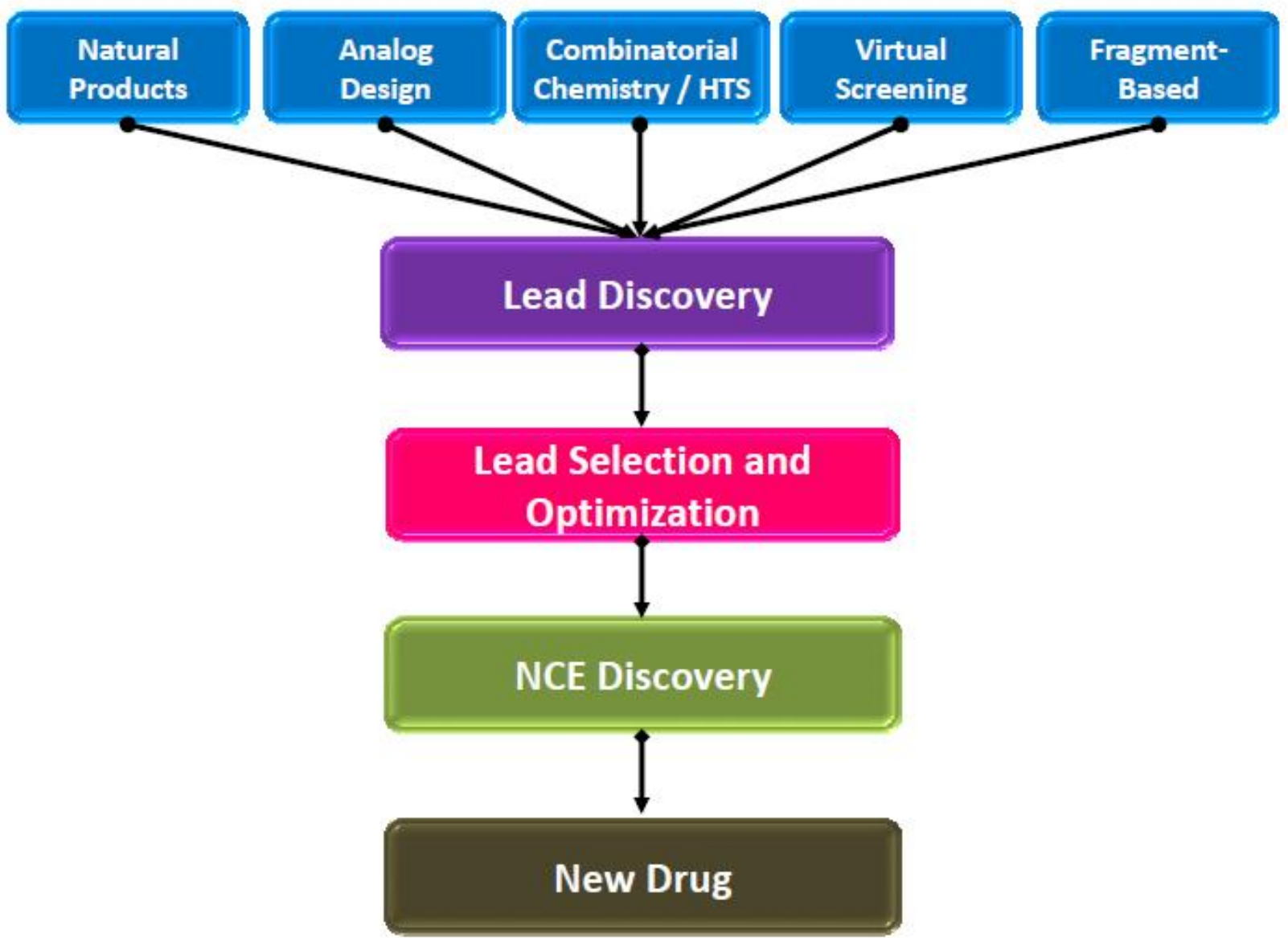

Figure 1: Drug discovery process.

In current scenario, the area of synthesizing new bioactive heterocyclic molecules, their designing, development and application is the most focused and challenging task for the researchers. Organic molecules bearing different heterocyclic ring systems have attracted a great deal of attention in nowadays, both in chemical and medicinal research that could be attributed to their different pharmacological 
applications. Synthetically produced heterocycles designed by organic chemists are used for instance as pharmaceuticals, dyestuff, agrochemicals and are of increasing importance in many other areas including adhesives, molecular engineering, polymers etc. Naturally occurring heterocyclic moieties played a vital role in biological processes. They are broadly found in naturally in plant alkaloids, nucleic acids, anthocyanins and flavones as well as in haem and chlorophyll. Additionally, several proteins, hormones, vitamins contain aromatic heterocyclic ring system [5]. Heterocycles have enormous potential as the most promising scaffolds as lead structures for the design of newer drugs. Heterocycles act as bioactive agents because they have specific chemical reactivity and they give convenient building blocks to which pharmacologically active substituents can be attached.

Despite the relative maturity of the field of organic chemistry, molecules continue to present synthetic chemists with significant challenges, especially as the expectations for synthetic, material, and energy efficiency continue to intensify. In response to these challenges, organic chemists have continued to develop innovative new synthetic methods. Many of these recently developed synthetic methods allow for achievement of ever more impressive chemo-, enantio-, diastereo-, and regioselectivity. Nowadays, certain transition metals including palladium, copper, iron, rhodium, ruthenium etc. are widely used to construct $\mathrm{C}-\mathrm{C}, \mathrm{C}-\mathrm{N}, \mathrm{C}-\mathrm{S}$ and $\mathrm{C}-\mathrm{O}$ bond. Cross-coupling reaction offers alkenylation, alkylation, arylation, amination, alkynylation etc. in regioselective mean. Along with coupling-, substitution- and elimination reaction is also a promising chemistry and often deals with wide knowledge of organic chemistry. Thus, we needed the development of innovative methodology for bioactive heterocycles in synthetic organic and medicinal chemistry with some advantages including its simplicity of operation, greener approach, easy workup procedure, selectivity, higher yields, and high-atom economic [6].

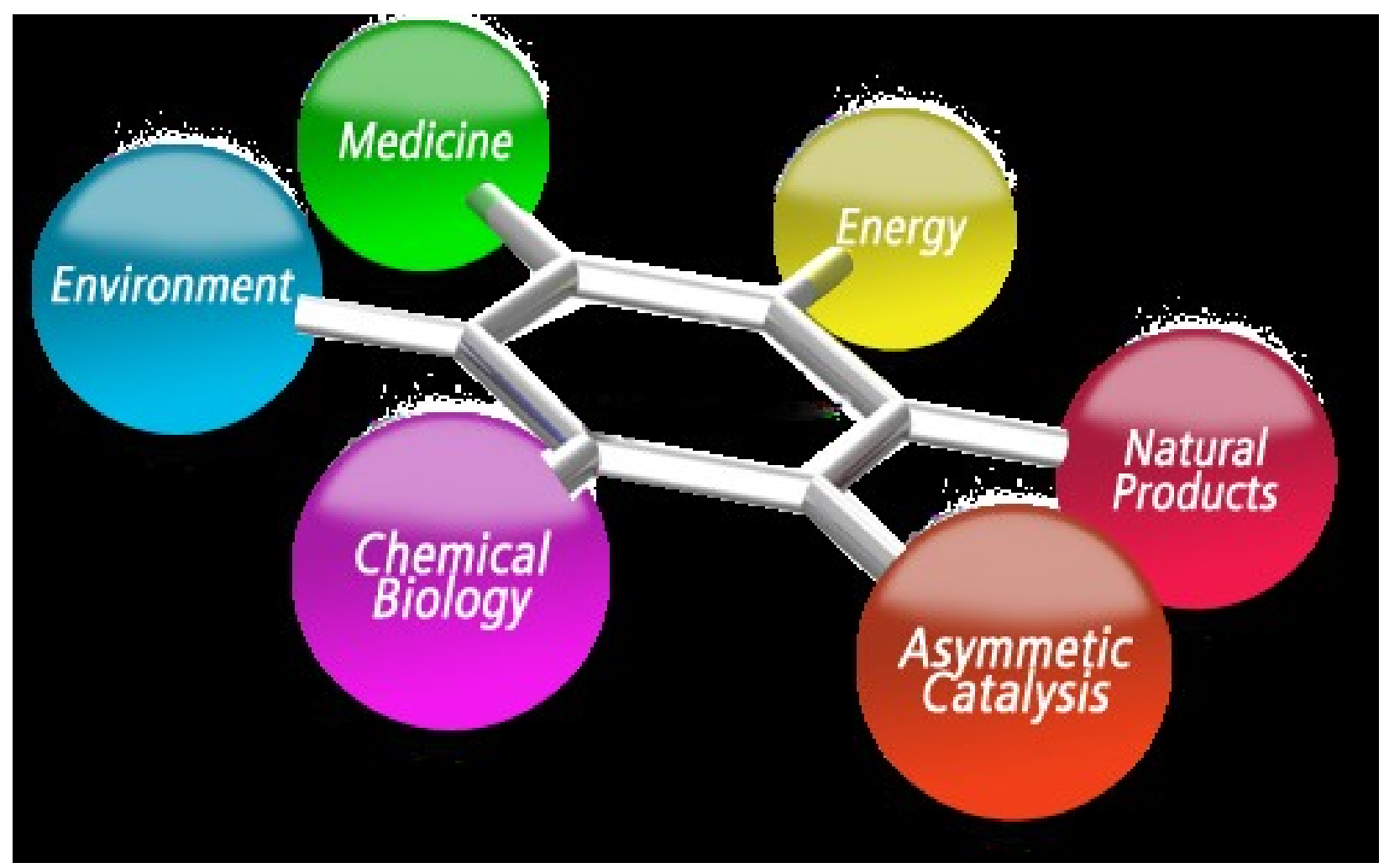

Figure 2: Uses of Organic Chemistry.

\section{References}

1. Sethi KK, Verma SM (2014) A systematic quantitative approach to rational drug design and discovery of novel human carbonic anhydrase IX inhibitors. J Enzyme Inhib Med Chem 29: 571-581.

2. Rahman MM, Karim MR, Ahsan MQ, Khalipha ABR, Chowdhury MR, et al. (2012) Use of computer in drug design and drug discovery: A Review. Int J Pharm Life Sci 1: 1-21.

3. Perez-Nueno V (2016) Towards the integration of Quantitative and Pharmacology into Drug Discovery: a system level understanding of therapeutic and toxic effects of drugs. Curr Pharm Des 22: 6881-6884.
4. Patel HM, Noolvi MN, Sharma P, Jaiswal V, Bansal S, et al. (2014) Quantitative structure-activity relationship (QSAR) studies as strategic approach in drug discovery. Med Chem Res 23: 4991-5007.

5. Arora P, Arora V, Lamba HS, Wadhwa D (2012) Importance of heterocyclic chemistry. Int J Pharm Res Sci 3: 2947-2954.

6. Babaev EV (2017) Incorporation of Heterocycles into Combinatorial Chemistry. Springer International Publishing, Switzerland. 